\title{
Planejamento educacional e gestão democrática: dimensões política e instrumental no PAR
}

\author{
Educational planning and democratic management: political and instrumental \\ dimensions in the PAR \\ Planificación de la educación y gestión democrática: dimensiones política e \\ instrumental en PAR
}

\section{GILMAR BARBOSA BARBOSA GUEDES MARIA GORETTI CABRAL BARBALHO}

\begin{abstract}
Resumo: $\mathrm{O}$ artigo reporta-se a uma investigação acerca da implementação do Plano de Ações Articuladas (PAR). Tem como objetivo analisar, em municípios do Rio Grande do Norte, as vertentes do planejamento educacional nesse processo, focalizando os indicadores relativos à área da gestão democrática. $\mathrm{O}$ estudo aponta que os municípios tendem a assumir a gestão com características dos modelos gerencial, democrático-participativo ou uma síntese dos dois, a depender dos interesses econômicos, das condições geopolíticas e da cultura organizacional do contexto.
\end{abstract}

Palavras-chave: Política educacional; planejamento educacional; gestão democrática; PAR; qualidade da educação.

Abstract: The article refers to the research about the implementation of the
Articulated Actions Plan (PAR). It aims to analyze several aspects of the
educational planning during this process of implementation in the municipalities
of Rio Grande do Norte, focusing on indicators related to the area of the
democratic management. The study points out that the cities tend to assume
characteristics of managerial models, democratic participatory, democratic
participative policy, or a synthesis of both, depending on the economic interests,
on the geopolitical conditions, and on the organizational culture in that context.

Keywords: Educational politics; educational planning; democratic management; PAR; education quality.

Resumen: El artículo hace referencia a una investigación acerca de la aplicación del Plan de Acciones Articuladas - PAR. Tiene como objetivo analizar los aspectos de la planificación de la educación en este proceso en los municipios de Rio Grande do Norte, centrándose en los indicadores relacionados con el área de gestión democrática. El estudio sugiere que las ciudades tienden a hacerse cargo de la gestión con las características de los modelos gerencial, democrático participativo o una síntesis de ambos, dependiendo de los intereses económicos, de las condiciones geopolíticas y la cultura de la organización del contexto.

Palabras clave: Política educativa; planificación de la educación; gestión democrática; PAR; calidad de la educación. 


\section{PLANEJAMENTO EM EDUCAÇÃO: REFLETINDO SIGNIFICADOS}

Planejar antecede, acompanha e sucede a organização da vida privada, institucional ou empresarial, cujas decisões são presididas por dada racionalidade na escolha de alternativas plausíveis. Implica conhecimento global e sistemático da realidade sobre a qual incidem as ações, visando a rupturas e/ou a continuidades. Requer, por isso, acompanhamento, controle e avaliação, caracterizando-se como processual e flexível.

No campo educacional, planejar implica orientar-se por concepções de sociedade, de pessoa, de educação, de cidadania para direcionar o conjunto das decisões políticas. Nesse sentido, prenuncia as possibilidades de se ter uma educação com qualidade social referenciada em todos os níveis etapas e modalidades de ensino. O planejamento direciona, por conseguinte, a agenda governamental nas instâncias constitutivas de poder, e, desse modo, nas etapas de formulação, de implementação e de avaliação, deve circunscrever-se ao âmbito nacional, estadual, municipal e escolar.

No domínio desse estudo, entendemos o significado de plano como um documento, com estatuto legal, que formaliza "[...] as decisões tomadas no processo de planejamento" (BORDIGNON, 2014, p. 33). Nesse sentido, por se tratar de processo que mantém intersecção entre meios e fins de recursos e de objetivos, visando à boa performance institucional ou de qualquer ação humana, pode apresentar-se sob distintos pontos de vista.

Consiste, assim, em um ato cujo fim é assegurar eficiência e eficácia de qualquer procedimento, demanda de previsão, coordenação, sistemática e tomada de decisão. No entendimento de Garcia e Queiroz (2009),

O planejamento parte da análise concreta das relações interpessoais e interinstitucionais, do contexto sócio-histórico e organizacional, da problemática da realidade, para compreender e intervir nas práticas cotidianas à luz de um referencial teórico-metodológico (p. 92).

Sendo esse um processo multifacetado, impõe-se como estratégia de poder que contribui ou para manter o status quo de uma minoria ou para promover a transformação social. Assim, em sua dimensão política, alinha as decisões em meio a interesses conflitantes, possibilitando o controle social das ações estatais. Enquanto ferramenta técnica, contribui para organizar a agenda governamental, contemplando prioridades econômicas, políticas e sociais, em face aos problemas rumo ao desenvolvimento econômico. 
Sob esse ângulo, considera Scaff (2007) que "[...] as agências de cooperação internacional desempenharam um importante papel na implantação do planejamento econômico e educacional brasileiro, em diversos momentos da história do País" e que “[...] o enfoque administrativo trazido pela Cepal considera o planejamento como instrumento de eficiência administrativa por meio da escolha dos melhores métodos para o alcance dos objetivos, racionalizando a ação do Estado" (p. 334). Essa assertiva nos leva a identificar um processo de intervenção das instituições multilaterais que formatam o planejamento no Brasil, no qual predomina o enfoque econômico enquanto mediação teórico-metodológica.

No pós-guerra os governos dos estados-nação, sob a chancela de organismos multilaterais - Banco Mundial (BM), Fundo Monetário Internacional (FMI), Organização das Nações Unidas para a Educação, Ciência e Cultura (UNESCO), Organização Mundial do Comércio (OMC), Comissão Econômica para América Latina e o Caribe (CEPAL), Comitê Regional Intergovernamental do Projeto Principal de Educação para a América Latina e Caribe (PROMEDLAC) - advogam a necessidade de realização do planejamento das políticas sociais estatais. O planejamento tornou-se prioridade nos países que seguem a matriz capitalista, oligopolista e expansionista, sob influência norte-americana, como também, nos países que seguem o modelo de desenvolvimento planificado pelo Estado Soviético.

Os países subdesenvolvidos passam a implementar, a partir de meados dos anos 1940, políticas de planejamento visando ao desenvolvimento econômico e social, no intuito de superar a lógica excludente característica da divisão internacional do trabalho. Os países enquadrados nesse perfil buscavam, de todas as formas, diminuir os indicadores de pobreza e exclusão social. Nos anos 1950, por exemplo, o planejamento educacional era pautado pela diversidade no atendimento a distintos segmentos da sociedade. Para as elites, uma educação do tipo propedêutica, que preparava para o exercício de profissões consideradas nobres: medicina, direito, engenharia. Para a classe média, profissões intermediárias procedentes das ciências humanas e algumas das ciências sociais com relativo prestígio. Para os segmentos pobres da população, a oferta era de educação de base profissional, destinada aos jovens, potenciais trabalhadores na indústria, dentre outros campos de atividade.

No caso nacional, os governos, utilizando o planejamento centralizado e autocrático buscavam caminhos diversos, dependendo da concepção políticoideológica da presidência e dos partidos políticos que lhe davam sustentação. Alguns governos implementavam um modelo de planejamento e de desenvolvimento que reduzisse a dependência econômica do país do capital externo, enquanto outros se alinhavam ao modelo oligopolista expansionista do capital internacional. 
Nesse sentido, o governo de Juscelino Kubischek de Oliveira (1956-1961), dando prosseguimento ao Plano Salte (Saúde, Alimentos, Transporte e Energia) de seu antecessor Eurico Gaspar Dutra (1948), teve como marca o Plano de Metas, abandonado por seu sucessor Jânio Quadros (1961). Esse plano contemplava a educação "[...] como demanda derivada do projeto de desenvolvimento nacional" (BORDIGNON, 2014, p. 43). Atendia aos imperativos da abertura do mercado brasileiro às multinacionais, principalmente, a indústria automobilística.

Em paralelo ao desejo de manutenção do status quo, no Brasil, uma contraideologia mobilizava setores da sociedade, de modo particular no Nordeste brasileiro, em torno de Movimentos de Cultura Popular (Recife). Ao lado desse contingente de iniciativas, difundiram-se, também, nas periferias das cidades e no campo, ações emanadas de setores da Igreja Católica para a educação, na forma de escolas radiofônicas, do Movimento de Educação de Base (MEB). No alvorecer dos anos de 1960, vislumbrava-se, assim, um novo projeto de educação de natureza "popular", e, portanto, de transformação social.

Uma das características da política de planejamento desenvolvimentista implantada pelos governos civis-militares (1964-1985) para atender à demanda por trabalhador especializado é a formação de mão de obra orientada pela teoria do capital humano ${ }^{1}$, tornando a educação a base para o desenvolvimento econômico.

Com o golpe civil-militar, a ênfase no econômico predominou no planejamento do campo educacional, e, doravante, não foi abandonada. Tanto que os planos de educação apresentavam-se como planos setoriais emanados das diretrizes dos Planos Nacionais de Desenvolvimento, com margem para acordos de empréstimos no mercado financeiro internacional, em especial o Banco Mundial e o Banco Interamericano de Desenvolvimento (TORRES, 1996). Prevaleceu a abordagem tecnocrata, que fortalecia o ideário dos economistas em contraposição ao dos educadores (BORDIGNON, 2014). Os dois últimos governos civis-militares e o governo que veio com a Nova República incorporaram ao planejamento das políticas educacionais certas demandas por participação advindas dos movimentos de redemocratização do país nas décadas de 1970 e 1980

As possibilidades de mudança no modelo de planejamento normativoburocrático incorporado pelo paradigma neoliberal delineiam-se em meados dos anos de 1970, nas crises do petróleo e no Acordo de Bretton Woods. Esses acontecimentos acarretaram a flutuação e a elevação cambial do dólar e,

1 Conforme Frigotto (1999, p. 41, grifos no original): "O conceito de capital humano - ou, mais, extensivamente, de recursos humanos - busca traduzir o montante de investimento que uma nação faz ou os indivíduos fazem, na expectativa de retornos adicionais futuros. [...] A tese central da teoria do capital humano que vincula educação ao desenvolvimento econômico, à distribuição de renda, configurando-se como uma ‘teoria de desenvolvimento' [...]”.

134 - RBPAE - v. 32, n. 1, p. 131 - 149 jan./abr. 2016 
consequentemente, levaram à falência fiscal dos estados-nação tomadores de empréstimos, sobretudo os da América Latina e do Caribe. O ajuste fiscal foi exigido como condição para o credenciamento à tomada de novos empréstimos pelos países.

As políticas educacionais nas décadas e 1980 e 1990 desenham-se a partir de duas vertentes de gestão pública: a democrática, originária dos movimentos sociais inseridos no processo de redemocratização do país e a de cunho gerencial, oriunda dos ideais neoliberais. Esses posicionamentos inauguram uma nova fase no cenário institucional, político e administrativo brasileiro. Do ponto de vista institucional, a Constituição Federal de 1988 aponta uma diretriz democrática, por meio do protagonismo decisório da sociedade civil e outra, pautada na perspectiva da performatividade capitalista, adotada pela reforma do Estado.

Por conseguinte, a estratégia de descentralização administrativa e financeira, emanada dos movimentos de redemocratização e defendida no ideário neoliberal numa perspectiva gerencial, tão presente nos propósitos da atual política de educação desde a década de 1990, inscreve-se no marco das funções do Estado e da supremacia do mercado como reguladores da vida em sociedade.

Ainda nesse decênio, a Lei n 9.394/1996 que regulamenta as Diretrizes e Bases da Educação Nacional (LDB/1996), ao instituir em seu art. 87 @ $1^{\circ}$ a Década da Educação, reforça a obrigatoriedade de elaboração do Plano Nacional de Educação em consonância com a Declaração Mundial sobre Educação para Todos, realizada em Jomtien na Tailândia (1990). Embora se considerem outras variáveis, o não cumprimento das metas definidas no Plano Nacional de Educação (PNE/2001-2011) foi um dos fatores que induziram à instituição do Plano de Desenvolvimento da Educação (PDE), sendo instituído, pelo Decreto no 6.094, de 24 de abril de 2007, o Plano de Metas Compromisso Todos pela Educação, no contexto do Plano Plurianual (PPA) 2007/2011, criado pela Lei no 11.653 , de 7 de abril de 2008 (BRASIL, 2008a).

Assim, em educação, o planejamento tende a não ser mais conduzido por um governo datado, com ênfase no modelo burocrático, com característica patrimonialista e clientelista, com caráter transitório e, carecendo, desse modo, de continuidade nas ações. Mudara, portanto, o perfil da condução na política brasileira, requerendo novos atributos do planejamento, os quais se traduzem no exercício de um pensar reflexivo a propósito das diretrizes que determinam o fazer coletivo. Fica, portanto, caracterizado como um ato de "[...] cunho político-pedagógico, visto que patenteia intuitos e intencionalidades, mostrando o que se deseja e o que se quer alcançar. Tal compreensão condiciona a pensar o planejamento como instrumento de implantação e implementação da gestão democrática” (BARBALHO; FERREIRA, 2012, p. 149). 


\section{GESTÃO DEMOCRÁTICA E A QUALIDADE DA EDUCAÇÃO}

Há na conjuntura social recente um aprofundamento do debate acerca do planejamento e da gestão democrática no campo educacional, entre outros fatores relacionado à luta pela qualidade da educação. A garantia do padrão de qualidade se constitui em um dos princípios fundamentais para a educação, conforme determina a Constituição Federal de 1988(Inciso VII do artigo 206) (BRASIL. 1988).

Ressaltamos que a garantia e a validação da qualidade em educação passam, antes de tudo, pela assimilação do que seja qualidade nessa arena. Inúmeras visões têm sido expostas, algumas se assemelhando, enquanto outras apresentam variantes quase que imperceptíveis. Há, ainda, há aquelas que são assaz divergentes, produzindo uma perspectiva polissêmica nas apreciações sobre a qualidade em educação, trazendo, pois, a compreensão de que essa dimensão envolve múltiplos significados. Apesar disso, e ainda que idealizada sob as mais diferentes perspectivas, qualidade no campo educacional abarca as estruturas, os métodos e os resultados nessa área e, desse ponto de vista, atualmente, é utilizada como parâmetro para referendar a eficiência, a eficácia, a efetividade e a relevância desse setor em todas as suas instâncias.

No cenário socioeconômico contemporâneo, buscando-se um ajustamento no conjunto de facetas imputadas, a qualidade dispõe de um balizamento a partir do qual se consideram cinco fatores relevantes para sua definição: “os educandos, o contexto socioeconômico nacional, os recursos materiais e humanos, o processo de ensino e aprendizagem e os resultados e benefícios da educação". Assim, "concentrando-se sobre estes aspectos, bem como a sua interação, é possível definir uma descrição para entender o que é a qualidade, para monitorar e melhorá-la” (PREAL, 2005, p. 2, tradução nossa).

A agenda educacional no contexto das reformas nesse setor tem dado destaque, nos últimos 25 anos, à qualidade, fortalecendo a discussão e, sobretudo, apresentando um discurso favorável a sua melhoria. Apesar disso,

\footnotetext{
A busca pela melhoria da qualidade em educação tem sido um processo tenso causado pelo que se espera melhorar e os recursos orçamentários disponíveis para tanto. Isso tem concorrido para o fortalecimento da ótica daqueles que defendem a compreensão de qualidade sustentada nas ideias de eficiência e de produtividade, de base empresarial, implicando, também, na adoção de uma perspectiva gerencial e, assim sendo, situa-se diferentemente da premissa de educação democrática em que sobressai o conceito de qualidade como crítico, político, sociológico (BARBALHO; FERREIRA, 2012, p. 144).
} 
Parafraseando Vasconcelos (s/d) pergunta-se: a quem interessa uma educação de qualidade? Essa é uma questão recorrente e que torna a busca pela qualidade um dos grandes desafios na área educacional. Nessa perspectiva, periodicamente verifica-se a proeminência ou não do debate sobre a qualidade da educação brasileira, ou seja, cada conjuntura política, econômica e social que se apresenta orienta a discussão da temática segundo os interesses dominantes.

As políticas recentes gestadas para esse campo trazem a marca de um tempo e espaço globalizados, configurados, nomeadamente, a partir de uma coerência mercadológica que concebe a qualidade vinculada a "uma noção produtivista de resultados e firmada nos parâmetros da razão instrumental e calculista que constituem a base do sistema sociometabólico do capital" (SOUZA, 2010, p. 66).

Caso sejam observados sob a ótica desse contexto, os objetivos e as finalidades traçadas pretendendo-se uma educação de qualidade não são alcançados via processos efetivamente democráticos, visto que a qualidade é idealizada com a função de cumprir ações metodológicas sustentadas por instrumentos próprios para o alcance de determinados fins.

$\mathrm{Na}$ conjuntura atual, a busca pela qualidade educacional tem sido pautada em políticas pensadas e implementadas com embasamento no ideário neoliberal e, de acordo com Hipólito (2011), têm sido marcadas por dois distintos e intrínsecos períodos:

Um, mais definido pela criação e implementação dos exames, testes, classificações (rankings), políticas de avaliação em larga escala, definição de padrões curriculares nacionais/regionais e formas de certificação. Outro, melhor identificado mais recentemente, caracteriza-se por introduzir, de forma mais agressiva, as parcerias público-privadas, as relações de quase-mercado, com profundas mudanças na gestão e na organização escolar, a partir de modelos tipicamente gerencialistas [...]. De fato, é um único processo com momentos distintos, mas constitutivos das mesmas políticas (p. 62).

No âmbito deste artigo, entende-se a organização e a gestão da educação numa perspectiva democrática, o que implica considerá-la como promotora de autonomia institucional, visto que se constitui em processo de descentralização de poder, assim como de participação.

Um dos princípios fundamentais da educação, estabelecido no Art. 206, inciso VI, da Constituição Federal de 1988, é a gestão democrática do ensino público. A institucionalização da LDB no 9.394/1996 estendeu o princípio constitucional, definindo que a gestão democrática atendesse às especificidades locais, afiançando a participação dos profissionais da educação na produção do projeto pedagógico da escola, assim como da comunidade escolar, em conselhos escolares ou órgãos 
similares. Promove-se, desse modo, a descentralização dos sistemas de ensino por meio da incorporação de mecanismos de autonomia pedagógica, administrativa e financeira das unidades escolares (BRASIL, 1996). O Plano Nacional de Educação, consagrado pela Lei no 10.172, de 9 de janeiro de 2001, instituiu, em suas diretrizes, a "gestão democrática e participativa" a ser materializada pelas políticas públicas educacionais, sobretudo quanto à organização e consolidação dos mecanismos da gestão educacional. Assim,

\footnotetext{
No contexto da redemocratização do Estado brasileiro, foi possível a inserção de diversos instrumentos normativos na perspectiva da configuração de um modelo de gestão democrática. Em grande parte, essas diretrizes satisfazem às demandas históricas das lutas em defesa da educação pública, nas quais a gestão democrática vem ocupando lugar de destaque (GARCIA; BATISTA, BARBOSA JÚNIOR, 2009, p. 122).
}

É nessa conjuntura de reformas educacionais que abarca as duas primeiras décadas dos anos 2000, permeada de contradições ideológicas, econômicas e políticas, inspiradas por diferentes matizes de planejamento educacional e num momento em que a temática da qualidade da educação norteia as políticas públicas nessa área, que são criados os planos e programas que buscam corporificar políticas para a gestão que assumam características dos modelos gerencial ou democráticoparticipativo e/ou uma terceira categoria híbrida resultante da comunhão desses dois modelos.

É sob o amparo dessas concepções de planejamento educacional que é criado o PDE, plano que, dentre suas diretivas, buscou promover a adesão de todos os estados e municípios brasileiros ao Compromisso Todos pela Educação. O Compromisso prevê dentre suas ações a implantação do Plano de Ações Articuladas (PAR), do qual discutiremos os elementos teóricos sistematizados por meio da pesquisa em rede Avaliação do Plano de Ações Articuladas (PAR) um estudo nos municípios do Rio Grande do Norte, Pará e Minas Gerais, no periodo de 2007 a 2011.

\section{O PLANEJAMENTO EDUCACIONAL NO PAR: A GESTÃO DEMOCRÁTICA EM FOCO}

No início do segundo mandato de Luiz Inácio Lula da Silva (2003-2010), é instituída uma política de planejamento educacional erigida a partir de uma matriz caracterizada por uma conjunção de programas de diferentes nuances, a exemplo do PDE, que, por sua vez se constitui parte do Programa de Aceleração do Crescimento (PAC), política assinalada como de caráter desenvolvimentista. 
Nesse contexto, no âmbito do PDE, insere-se o PAR, concebido como uma política de planejamento estratégico em que os estados e os municípios fazem a adesão ao Plano de Metas Compromisso Todos pela Educação por meio da assinatura de um termo de acordo. Na implantação do Plano, a administração local é assessorada por uma equipe de especialistas, sob a orientação do MEC, buscando, por meio de um diagnóstico, avaliar a situação educacional do ente federado (estado ou município). O diagnóstico leva em consideração as dimensões gestão educacional; formação de professores e de profissionais de serviços e apoio escolar; práticas pedagógicas e avaliação e, infraestrutura física e recursos pedagógicos, de forma a detectar os aspectos que dizem respeito à qualidade da educação oferecida pelo ente federado.

Como experiência da práxis planejamento educacional nos aspectos relativos ao PAR, discutem-se dados sistematizados pela pesquisa em rede, vinculada ao Programa Observatório da Educação/Coordenação de Aperfeiçoamento de Pessoal de Nível Superior (OBEDUC/CAPES); trata-se de dados relativos ao PAR implementados nos municípios de Acari, Natal, Mossoró, Riachuelo e São José de Campestre, localizados no Estado do Rio Grande do Norte 2 .

A referida pesquisa objetiva analisar o impacto da implementação do PAR, a partir da observação dos aspectos quantitativos e qualitativos observados nos municípios delineados para amostra nos Estados de Pará, Minas Gerais e Rio Grande do Norte, fazendo uma mediação com as discussões teóricas e os dados coletados na pesquisa macro citada.

De acordo com o Guia Prático de Ações do PAR (2007), a dimensão da Gestão Educacional está dividida em cinco áreas³. Focaremos as análises na área 1 - Gestão Democrática: articulação e desenvolvimento dos sistemas de ensino. Ressaltase que os Municípios que aderiram ao PAR realizaram, com assessoramento do MEC, um diagnóstico com o intuito de aferir as práticas de gestão democrática em desenvolvimento nas redes municipais. Os resultados obtidos por meio do diagnóstico atribuíram aos indicadores escores que variaram de 1 a 4; contudo, apenas as pontuações 1 e 2 representavam situações insatisfatórias ou inexistentes,

2 A pesquisa definiu como amostra a capital de cada estado da pesquisa, no caso do Rio Grande do Norte a cidade do Natal, dois municípios de alto IDEB (Acari e Mossoró) e dois municípios de baixo IDEB (Riachuelo e São José de Campestre).

3 Área 1 - Gestão Democrática: articulação e desenvolvimento dos sistemas de ensino; área 2 Desenvolvimento da Educação Básica: ações que visem a sua universalização, a melhoria da qualidade do ensino e da aprendizagem assegurando a qualidade nas condições de acesso e permanência e conclusão na idade adequada; área 3 Comunicação com a sociedade; área 4 - Suficiência e estabilidade da equipe escolar e área 5 Gestão de finanças (BRASIL, 2007c). 
que poderiam gerar ações a serem implementadas com recursos do PAR. Ainda se conferia a pontuação 0 , caso o ente federado considerasse que aquele indicador não se aplicava às condições do município.

A seguir, analisam-se os nove indicadores, apresentados o gráfico 1, relativos à gestão democrática: 1) Conselho Escolar (CE); 2) Conselho Municipal de Educação (CME); 3) Conselho de Alimentação Escolar (CAE); 4) Projeto Pedagógico (PP); 5) escolha da direção das escolas; 6) Plano Municipal de Educação (PME); 7) Plano de Carreira para o Magistério; 8) estágio probatório de professores e demais profissionais da educação; e, 9) Plano de Carreira para os profissionais de serviços e apoio escolar.

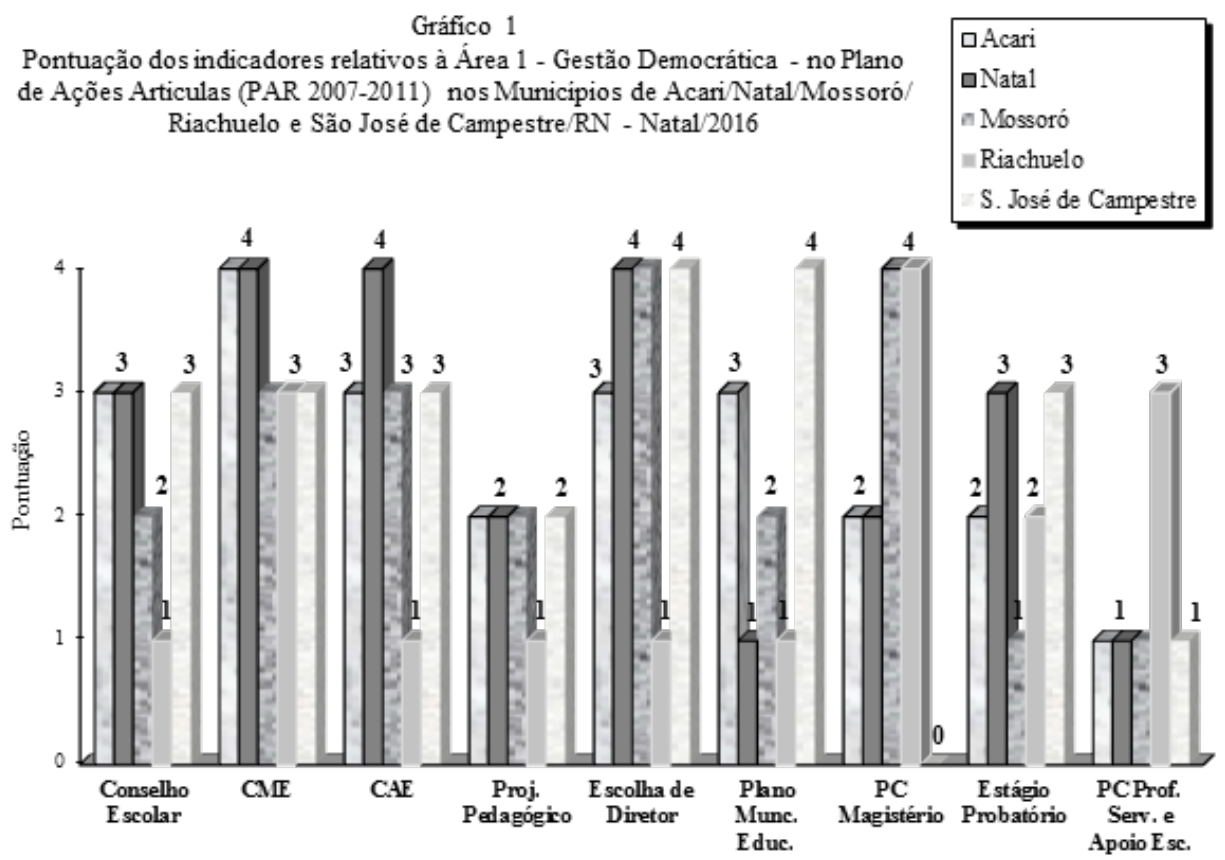

Fonte: Dados do Projeto_Avaliagão do Plano de Açäes Articuladas (PAR): von estudo emmuricípior dos estadbs

O primeiro indicador analisado diz respeito ao conselho escolar ao qual foi atribuída pontuação 3 nos municípios de Acari, Natal e São José de Campestre e valores 2 e 1 a Mossoró e Riachuelo, respectivamente. Observa-se que nenhum dos municípios, independente da condição geográfica, da importância socioeconômica e política ou mesmo do índice do IDEB conseguiu atingir o patamar de avaliação 4. Mesmo aos municípios que tiveram pontuação 3 nesse indicador, era citada uma justificativa recorrente para não se atribuir a pontuação 4, como a frequência reduzida e irregular de reuniões desse colegiado nas escolas das redes municipais. 
O município de Mossoró avaliou a atuação dos conselhos escolares com a pontuação 2, nota essa atribuída considerando-se a justificativa de que o município não focava seu planejamento educacional numa diretriz alinhada com os princípios da gestão democrática, mas apresentava uma conformação de gestão em consonância com o modelo gerencial. Isso, porque o município havia assinado acordos com instituições pertencentes ao terceiro setor, que adotam esse modelo de gestão. Conforme Albuquerque (2010, p. 53) o município de Mossoró/RN, em 1998, “[...] assinou o primeiro pacto de cooperação com o Instituto Ayrton Senna [...]”. A gestão pactuou para implantação nas unidades escolares e secretaria os programas: Escola Campeã e Gestão Nota 10, desenvolvidos entre 2005 e 2009.

No período de implantação do PAR em Mossoró, os conselhos escolares não encontraram base, política e administrativa para desenvolver-se, pelo fato de a gestão municipal focar-se numa diretriz fundada nos princípios da eficiência e da eficácia dos resultados educacionais, respaldada pela lógica da performatividade, defendida pela Fundação Airton Senna. Portanto, eram restritas as condições para implantação de uma diretriz de gestão democrática, que Libâneo (2013) concebe como aquela que

[...] Baseia-se na relação orgânica entre a direção e a participação dos membros da equipe. [...] Advoga formas de gestão participativa, mas não exclui a necessidade de coordenação, de diferenciação de competências profissionais entre os membros da equipe, de gestão eficaz e de avaliação sistemática da execução das decisões tomadas (p. 104, grifo nosso).

Em contraposição à concepção democrático-participativa referida, o município de Mossoró se reestrutura administrativamente criando a Gerência Executiva da Educação e Desporto, abandonando, assim, o formato de Secretaria Municipal de Educação, comum aos demais municípios do Rio Grade do Norte. Adota-se a diretriz de se ampliarem as parcerias público-privadas, encaminhamento seguido por uma parcela representativa das gestões municipais que se filiam à nova gestão pública orientada pelo modelo gerencial. Os intelectuais e gestores defensores dessa concepção de gestão afirmam que o município receberá assessoria técnica no intuito de se buscar a superação do analfabetismo e do fracasso escolar, sem, contudo, onerar os recursos públicos.

De acordo com esse modelo gerencial de gestão, a autonomia é individualizada e a participação implica responsabilização dos sujeitos pelos resultados do trabalho. Firmam-se os contratos de gestão para que as instituições produzam de forma eficaz e eficiente. O que se busca na verdade é a adequação às disposições mercadológicas, implementando-se as estratégias de acumulação do capital às políticas educacionais, o que incide sobre mostrar bons resultados 
mediante o fortalecimento dos laços entre escolarização, trabalho, produtividade, serviços e mercado para melhorar a economia nacional (AZEVEDO, 2003).

Dentre os municípios avaliados, Riachuelo foi o único que atribuiu uma nota 1 ao indicador do conselho escolar, condição que denota uma situação precária referente à atuação desses colegiados, sendo necessária, inclusive, a criação dos conselhos escolares no município. Para equacionar essa situação negativa, a gestão municipal propôs a implantação de quatro subações e estratégias.

Os dados do gráfico 1, no tocante aos indicadores: 2) Conselho Municipal de Educação (CME) e 3) Conselho de Alimentação Escolar (CAE) apresentam dados satisfatórios, que variam entre o patamar de 3 e 4, o que ocorre em função de uma demanda legal e institucional do Estado e da sociedade civil brasileira para que esses conselhos assumam uma condição fiscalizadora da gestão pública. Os Conselhos de diferentes matizes consolidam-se "sob a influência da Constituição Federal de 1988 e dos princípios instituídos que buscavam aperfeiçoar o controle social e a participação da sociedade civil [...]" (GUEDES, FRANÇA E FERREIRA, p. 314), como também, pela necessidade de "[...] acompanhamento social, no qual a administração gerencial apregoa como princípio basilar a premissa do atendimento da accountability, isto é, da prestação de contas feita por gestores/ servidores públicos aos alunos tidos como os 'usuários dos serviços educacionais' [...]" (Idem, p. 314-315, grifos dos autores).

Os dados relativos aos planos municipais apresentam indicadores positivos em apenas dois pequenos municípios potiguares - Acari e São José de Campestre. Isto demonstra um arrefecimento do planejamento educacional na maioria dos municípios brasileiros no período que compreende o processo de criação e implementação do PDE/PAR e o consequente aleijamento da execução do PNE (2001/2011); nesse momento, a administração das redes escolares públicas ficou focada na implantação dos diversos programas de Governo vinculados ao PDE, em detrimento da criação e implementação de planos de Estado.

Conforme identificamos no gráfico 1, referente ao Projeto Pedagógico, os cinco municípios apresentam indicadores negativos. Um exemplo patente dessa condição insatisfatória pode ser diagnosticado no município de Natal, a capital do estado, que apresenta as condições econômicas e administrativas mais favoráveis, se a compararmos aos demais municípios estudados; mesmo assim, 30\% das escolas da rede municipal ainda não possuíam o PP quando da elaboração do PAR.

Outro aspecto negativo identificado em Natal e Riachuelo foi que as práticas de planejamento estratégico apontadas para criação, implementação e aperfeiçoamento do PP apresentavam uma sobreposição de ideias nos campos conceitual, pedagógico e administrativo entre as ações propostas para o PP e 
o PDE Escola, diagnosticando uma visão sobreposta e confusa dos gestores entre os programas de diretriz gerencial, semelhantes ao PDE Escola, e outros fundados numa perspectiva democrático-participativa da gestão, a exemplo do projeto político-pedagógico da escola. Nessa condição, o PP tende a ficar em segundo plano, observando a lógica gerencial característica do PDE Escola de administrar a instituição pública. Essa compreensão é endossada por Santos (2011), que afirma: "Por serem lógicas distintas, de fato, o PPP é subvalorizado frente ao PDE, apesar dos discursos contrários de seus gerentes e mentores” (p. 153).

No que se refere ao indicador relativo aos critérios para a eleição de dirigentes escolares, observa-se que a maioria dos municípios apresentou indicadores favoráveis, conforme constatado no município de Natal, que realiza eleições diretas para os diretores das escolas municipais desde o ano de 1986. Uma exceção é Riachuelo, que apresenta o indicador com escore 1; a explicação é que nesse município os diretores escolares são nomeados pelo gestor municipal, situação característica da maioria dos pequenos municípios potiguares (o município tinha uma população em torno de 7 mil habitantes em 2010), que na maioria das vezes, estão à mercê das características geopolíticas locais, numa conjuntura em que as práticas de democratização da gestão encontram entraves diversos como: política partidária clientelista, desmobilização da sociedade civil organizada e dos órgãos representativos dos trabalhadores em educação.

Marques (2011), ao analisar as redes municipais em que a assunção ao cargo de diretor ocorre por nomeação do gestor, afirma: [...] As secretarias apontam a existência de metas e ações no sentido da democratização que, em sua maioria, visam à qualificação da educação municipal, tais como formação, universalização, oferta de alimentação, entre outras (p. 7).

Nesse sentido, a discussão sobre a participação direta dos profissionais da educação na escolha dos seus dirigentes é desviada para reflexões de ordem diversas da gestão educacional, notadamente, aquelas direcionadas ao âmbito da administração macro das redes.

Em relação aos Planos de Carreira para o Magistério, identificamos que apenas dois municípios apresentam indicadores positivos quanto a sua existência, conforme preveem os princípios estatuídos pela CF/1988, no Art. 206, inciso $\mathrm{V}$, fundamentos novamente respaldados em 2008, por meio do art. $6^{\circ}$ da Lei $n^{\circ}$ 11.738/08, que prevê a elaboração e adequação dos planos de carreira tendo em vista o "cumprimento do piso salarial profissional nacional para os profissionais do magistério público da educação básica" (BRASIL, 2008b).

Concluindo a análise dos indicadores contidos no gráfico 1, observamos que os planos de carreira dos profissionais de serviços e apoio escolar praticamente 
inexistiam à época da implantação do PAR (2007-2011); e, em condição correlata, estava o cumprimento e a clareza das normas relativas ao estágio probatório dos profissionais da educação. Quando discutimos os indicadores relativos à valorização dos profissionais da educação, a exemplo dos planos de carreira e de valorização salarial, temos de entendê-los "como um bem social em disputa, no interior de uma espiral de luta sem perspectiva de término, articulada na tessitura social envolvendo aspectos múltiplos e profundamente imbricados" (ALVES, 2011, p. 149). Por isso, esses bens sociais em disputa precisam ser concretizados e atualizados continuamente; deve ser uma busca contínua e incessante dos educadores que lutam por uma educação pública, gratuita e de qualidade social.

\section{CONSIDERAÇÕES FINAIS}

O planejamento estatal brasileiro. adotando diretriz dos estados nacionais e dos organismos multilaterais, a partir da segunda metade do século $\mathrm{XX}$, tem sua gênese na busca pelo desenvolvimento econômico e social do país. É nessa diretiva que, a partir dos anos 1950, o foco do planejamento educacional assume uma dimensão de preparação da força de trabalho para ingressar no mundo do trabalho capitalista de matiz industrial taylorista/fordista. E, mais recentemente, notadamente a partir da Constituição Federal de 1988, o eixo passa a ser o oferecimento de uma educação de qualidade que prepare para o mundo do trabalho e a cidadania burguesa, centrada, dessa forma, no domínio de competências técnicas para inserção no setor produtivo capitalista e de habilidades sociais e políticas para viver em comunidade.

À luz dessa compreensão, cabe ao governo nacional criar as condições institucionais e concretas, planos e programas, que materializem essa modulação de diretrizes. Especialmente no campo das políticas educacionais, esse planejamento assume um tom de qualificação de capital humano e de preparação, na dimensão social e política, para ingresso dependente na sociedade, buscando-se com isso modular o ritmo de desenvolvimento capitalista.

Essa lógica de desenvolvimento nacional e, por sua vez, de planejamento educacional, imputa a programas, a exemplo do PDE/PAR, a necessidade de prover os diversos entes federados com assistência suplementar de recursos e assessoria administrativa que subsidie o planejamento dos sistemas de ensino. Ao analisar uma experiência pragmática de gestão, centrando-se na área da gestão democrática, notadamente, na dimensão dos conselhos representativos, ainda que os indicadores sejam positivos na maioria dos municípios, contraditoriamente, no diagnóstico do PAR, os gestores indicam haver uma participação circunstancial e superficial dos representantes desses colegiados. Essa condição, com baixos 
índices de participação acentua-se na administração municipal que adotou a matriz de programas gerenciais desenvolvidos por entidades sociais do terceiro setor, que, na maioria das vezes, buscam apenas a performatividade nos resultados de aprendizagem, sem preocupação em consubstanciar a democratização da gestão por meio da participação dos atores nas decisões políticas, administrativas e financeiras das secretarias e das escolas.

$\mathrm{Na}$ dimensão dos projetos pedagógicos, a condição de precariedade é recorrente em todas as redes municipais estudadas, com uma sensível diferença quanto à existência dos planos municipais de educação. Essa condição deixa patente que o planejamento político-pedagógico endógeno das escolas municipais e o exógeno, relativo ao planejamento estratégico das redes padeciam, naquela oportunidade, com os efeitos negativos do descumprimento do PNE-2001/2011 e com a prioridade atribuída pelos gestores aos aspectos gerenciais envolvidos na administração e no financiamento descentralizado, normalmente, em detrimento da dimensão político-pedagógica das redes e das escolas. Um exemplo dessa prioridade é o equívoco de entendimento dos gestores quanto à função gerencial - administrativo-financeira e pedagógica - do PDE Escola e a democráticoparticipativa do projeto político-pedagógico da escola.

Consideramos que o período de elaboração e vigência do PDE/PAR (2007/2011) é um momento histórico em que o capitalismo enfrenta uma de suas crises cíclicas de acumulação, denominada subprime, como a crise 2008 , que tem acarretado uma gradativa redução no fluxo de liquidez monetária dos estados nacionais que têm sido obrigados a ajustar os gastos às políticas sociais, inclusive, as educacionais.

A superação dessa crise, para os economistas neosociais ${ }^{4}$ e conservadores, virá pela utilização de concepções e práticas - privatização, terceirização, desregulamentação e austeridade fiscal - de gestão gerencial descendentes da reforma do Estado dos anos 1990. Ao adotar essa compreensão neo-conservadora de política econômica, os governos passam a instrumentalizá-la via criação e execução de diversos planos e programas governamentais, a exemplo do PDE/ PAR, que, mesmo apresentando mecanismos institucionais de gestão democrática

4 Para Silva (2009, p. 26) o Estado Neo-Social surgiu na contemporaneidade como um novo paradigma de estado, que seria resultado da síntese de determinadas características do Estado de Bem-Estar Social e do Estado de diretriz neoliberal; para tanto, assevera que: "O modelo de Estado neo-social está para o Estado social assim como Estado neoliberal está para o Estado Liberal. Apesar das <<parecenças familiares $>>$ entre os dois últimos (defesa de um Estado mínimo ou limitado, prioridade no equilíbrio das contas públicas e à estabilidade macroeconómica, preocupação centrada nos direitos civis e políticos, em detrimento dos direitos sociais), a verdade é que estamos perante dois modelos histórica e estruturalmente distintos. [...] O Estado neosocial distingue-se do Estado regulador pela relativa valorização dos imperativos de ordem social e política face aos imperativos de estabilidade macroeconómica. De resto, não é por acaso que a questão da legitimação social do regime democrático hoje se recoloca com premência". 
(Conselho Escolar e Projeto Pedagógico), ainda assim são programas que buscam, primeiramente a performatividade da administração pública. Práxis da performatividade, que fundada no modelo gerencial, tem levado ao esmaecimento do processo de democratização da gestão escolar pública e a uma lenta, velada e gradual privatização/terceirização da educação pública e gratuita de qualidade social.

\section{REFERÊNCIAS}

ALBUQUERQUE, Eugênia Morais de. A implantação do programa gestão nota 10 no sistema municipal de educação em Mossoró/RN. 2010, 181 f. Dissertação (Mestrado. em Educação) - Universidade Federal do Rio Grande do Norte. Natal, 2010.

ALVES, Maria do Socorro Valois. Financiamento da educação: uma visão geral sobre seus mecanismos e possibilidades de valorizar o magistério público. In: GOMES, Alfredo Macedo (org.). Políticas Públicas e Gestão da Educação. Campinas: Mercado das Letras, 2011, p. 119-152 (Série Estudos em Políticas Públicas e Educação).

AZEVEDO, Sérgio. Políticas públicas: discutindo modelos e alguns problemas de implementação. In: Santos Júnior, Orlando Alves dos et al. (Org.). Políticas públicas e gestão local: programa interdisciplinar de capacitação de conselheiros municipais. Rio de Janeiro: Fase, 2003. p. 38-44.

BARBALHO, Maria Goretti C.; FERREIRA, Maria Aparecida dos S. Planejamento e avaliação: concepção do gestor da escola pública do RN. In: CASTRO, Alda M. D. Araújo; BARBALHO, Maria Goretti C. (Org.) Formação de gestores a distância: uma contribuição para a gestão democrática da escola. Natal, RN: EDUFRN, 2012. p. 143-168.

BORDIGNON, Genuíno. Caminhar da Educação Brasileira: muitos planos, pouco planejamento. In: SOUZA, Donaldo Bello; MARTINS, Angela Maria (Org.). Planos de Educação no Brasil: Planejamento, Políticas, Práticas. São Paulo: Edições Loyola, 2014. p. 29-53.

BRASIL. Decreto n. $\mathbf{1 1 . 6 5 3}$, de 7 de abril de 2008. Dispõe sobre o Plano Plurianual para o período 2008/2011. Brasília/DF, 2008a. Disponível em: 
<http://www.planalto.gov.br/ccivil_03/_Ato2007-2010/2008/Lei/L11653. htm>. Acesso em: 15 jan. 2016.

Lei $\mathbf{n}^{\mathbf{0}} \mathbf{1 1 . 7 3 8}$, de 16 de julho de 2008. Instituiu o piso salarial profissional nacional para os profissionais do magistério público da educação básica. 2008b. Disponível em: <http://www.planalto.gov.br/ccivil_03/_ato2007-2010/2008/ lei/111738.htm>. Acesso em: 30 jan. 2016.

Plano de Metas Compromisso Todos pela Educação. Plano de Ações Articuladas - PAR 2007-2011: guia prático de ações. Brasília,DF, nov. 2007c. Disponível em:<http://www.dominiopublico.gov.br/download/texto/ me004761.pdf>. Acesso em: 20 mar. 2015.

Lei de Diretrizes e Bases da Educação Nacional. Lei no 9.394/96 de 20.12.1996. Estabelece as Diretrizes e Bases da Educação Nacional. Presidência da República. Casa Civil. Subchefia para Assuntos Jurídicos. Brasília/DF, 1996. Disponível em: <http://www.planalto.gov.br/ccivil_03/Leis/L9394.htm>. Acesso em: 15 de dez. 2015.

Presidência da República. Casa Civil. Subchefia para Assuntos Jurídicos. Constituição da República Federativa do Brasil de 1988. Presidência da República. Casa Civil. Subchefia para Assuntos Jurídicos. Brasília/DF, 1988. Disponível em: <http://www.planalto.gov.br/ccivil_03/Constituicao/ Constituicao.htm>. Acesso em: 30 jan. 2016.

FRIGOTTO, Gaudêncio. A Produtividade da Escola Improdutiva: Um (re) exame das relações entre educação e estrutura econômico-social capitalista. 5. ed. São Paulo: Cortez. 1999.

GARCIA, Luciane Terra dos Santos; QUEIROZ, Maria Aparecida de. Embates pedagógicos e organizacionais nas políticas de educação. Natal: EDUFRN, 2009.

GARCIA, Luciane erra dos Santos, BATISTA, Maria do Socorro da Silva; BARBOSA JÚNIOR, Walter Pinheiro. A construção da qualidade da educação brasileira fundamentada na avaliação e na gestão democrática. In: FRANÇA, Magna (Org.). Sistema Nacional de Educação e o PNE (2011-2020): diálogos e perspectivas. Brasília, DF: Líber Livro, 2009. p. 107-127. 
GUEDES; Gilmar Barbosa; FRANÇA, Magna; FERREIRA, Maria Aparecida dos Santos. Financiamento da Educação Básica e o Regime de Colaboração: FUNDEF, FUNDEB e o Conselho de Controle Social: a matrícula e recursos do RN (19962010). In: FRANÇA, Magna; MOMO, Mariangela. Processo Democrático Participativo: a construção do PNE. Campinas, SP: Mercado das Letras, 2014 (Série Educação Geral, Educação Superior e Formação Continuada do Educador). p. 289-324.

HIPÓLITO, Álvaro Moreira. Reorganização Gerencialista da Escola e Trabalho Docente. Educação: Teoria e Prática. v. 21, n. 38, p. 59-78, out./dez.2011.

LIBÂNEO, José Carlos. Organização e Gestão da Escola: teoria e prática. 6. ed. rev. e ampl. São Paulo: Heccus Editora, 2013.

MARQUES, Luciana Rosa. A Eleição de Diretores como Componente das Políticas de Descentralização/Democratização da Educação na Região Metropolitana do Recife. 25 $^{\circ}$ Simpósio Brasileiro de Política e Administração da Educação (ANPAE). São Paulo, 2011. Disponível em: <http://www. anpae.org.br/simposio2011/cdrom2011/PDFs/trabalhos Completos/ comunicacoesRelatos/0299.pdf.> .. Acesso em: 26 ago. 2011.

PREAL. Programa de Promoción de la Reforma Educativa en América Latina y el Caribe. Formas \& reformas de la educacion. Série Políticas. 2005.

SANTOS, Evson Malaquias de Moraes. As antinomias do planejamento do PDE nas escolas públicas: neoliberalismo numa terra patrimonialista. In: GOMES, Alfredo Macedo (Org.). Políticas Públicas e Gestão da Educação. Campinas,SP: Mercado das Letras, 2011, p. 153-184 (Série Estudos em Políticas Públicas e Educação).

SCAFF, Elisângela Alves da Silva. Cooperação internacional para o planejamento da educação brasileira: aspectos teóricos e históricos. Revista Brasileira de Estudos Pedagógicos, Brasília,DF, v. 88, n. 219, p. 331-344, maio/ago., 2007.

SILVA, Filipe Carreira da. Metamorfose do Estado: Portugal e a emergência do estado neo-social. In: CARMO, Renato Miguel; RODRIGUES, João (Org.). Onde Pára o Estado? Políticas públicas em tempos de crise. Lisboa, Portugal: Edições Nelson de Matos, 2009. p. 19-51. 
SOUZA, Luciene Maria de. Estado e politicas educacionais: reflexões sobre as teses neoliberais. In: FRANÇA, Robson Luiz de (Org.). Educação e trabalho: políticas públicas e a formação para o trabalho. Campinas, SP: Editora Alínea, 2010. p. 5771.

TORRES. Rosa María. Melhorar a qualidade da educação básica? As estratégias do Banco Mundial. In: TOMMASI, L. De; WARDE, J. M.; HADDAD, S. (Org.) O Banco Mundial e as políticas educacionais. São Paulo: Cortez;Ação Educativa/PUC-SP, 1996. p. 125-194.

VASCONCELLOS, Celso dos S. O Desafio da Qualidade da Educação. Texto Preparatório para a CONAE - s/d. Disponível em http:/ /www.celsovasconcellos. com.br/Download/CSV-Desafio_da_Qualidade.pdf. Acesso em 26 jun. 2014.

GILMAR BARBOSA BARBOSA GUEDES possui graduação em Pedagogia (1999), Mestrado (2002) e Doutorado (2007) em Educação pela Universidade Federal do Rio Grande do Norte (UFRN). Tem experiência na área de Educação, com ênfase em Política e Gestão da Educação, atuando principalmente nos seguintes temas: Gestão/administração Educacional, Organização Estudantil na Educação Básica e Financiamento Educacional. Professor Adjunto III do Departamento de Fundamentos e Políticas da Educação da Universidade Federal do Rio Grande do Norte. Professor vinculado ao Programa de Pós-graduação em Educação do Centro de Educação da UFRN. Membro da Comissão Assessora da Área de Pedagogia do INEP-ENADE-2014. E-mail: gbguedes@uol.com.br

MARIA GORETTI CABRAL BARBALHO Possui graduação em Pedagogia, Mestrado (2006) e Doutorado (2011) em Educação pela Universidade Federal do Rio Grande do Norte. Atualmente é professor associado da Universidade Federal do Rio Grande do Norte. Tem experiência na área de Educação, com ênfase em Política Educacional, atuando principalmente nos seguintes temas: política educacional, gestão escolar, gestão democrática, descentralização e educação superior, acesso, internacionalização. E-mail: goretti_cabral@yahoo. com.br

Recebido em fevereiro de 2016

Aprovado em abril de 2016 